ISSN: $2036-5438$

\title{
The Contribution of COSAC to Joint Parliamentary Scrutiny in the EU: A Practitioner's View
}

by

\author{
Bruno A. Dias Pinheiro*
}

Perspectives on Federalism, Vol. 10, issue 3, 2018 


\section{Abstract}

COSAC has played an active role in fostering and developing interparliamentary cooperation since it has proven to be an effective model that has helped shape a supranational layer of influence for NPs. The central question addressed here is to assess whether COSAC is currently structured to allow NPs to obtain more information and access to the policy and decision-making circuits at EU level and, therefore, if NPs are benefiting from COSAC or are they, on the contrary, lagging behind and lost amidst so many interparliamentary meetings?

It is argued that COSAC occupies a key role in the multipolarised system of interparliamentary cooperation, because it is the conference with the "global picture" and therefore in a unique position to bring coherence to the overall system. This paper therefore aims at putting forward some ideas and approaches regarding the role of COSAC in the effectiveness of interparliamentary cooperation, covering not only its present proceedings and output, but also some thoughts for further reflection on the future strengthening of COSAC.

Key-words

COSAC, interparliamentary cooperation, interparliamentary conferences, multipolarised system, COSAC reform, effectiveness in scrutiny of EU affairs, COSAC Secretariat 


\section{Introduction}

Exactly ten years have passed since the Treaty of Lisbon was signed at the Jerónimo's monastery in the Portuguese capital, enshrining, for the first time in European Union (EU) integration, the acknowledgement of the active role and involvement of national Parliaments (NPs) in EU affairs. ${ }^{\mathrm{I}}$ For decades, the European Treaties neither regulated, nor envisaged, any substantive relations between NPs and the European Community/European Union institutions. Their role in EU affairs was therefore largely overlooked and considered only as far as its domestic/national dimension was concerned.

The Conference of Parliamentary Committees for Union Affairs of the Parliaments of the European Union (COSAC) has played an active role in developing the effectiveness of inter-parliamentary cooperation for it has - as we attempt to demonstrate - proved to be an effective model and, to some extent, a pioneer in inter-parliamentary cooperation, playing a decisive role in mainstreaming the importance of NPs as actors that possess certain democratic qualities and responsibilities, including the maintenance of popular legitimacy, and the scrutiny of executive power in EU affairs.

This essay is written by a practitioner and a direct observer of these phenomena for exactly ten years, which almost coincides with the moment when the Treaty of Lisbon was brought to life. This has allowed me the privilege of witnessing its entry into legal force and its operative implementation, its interpretation and the changes it produced and induced in the behaviour of a number of players in the EU institutional system, in particular NPs. ${ }^{\text {II }}$

Thus, the approach taken is mostly empirical and heuristic, i.e. a standard technique based on professional experience to promote and develop a more in-depth knowledge of a scientific area, oriented towards problem-solving and the identification of new patterns of behaviour of the institutional actors who operate in this environment, i.e., NPs. From a theoretical perspective, a 'broader neo-institutionalist' approach is used, assuming that institutions are not neutral containers fulfilling certain functional needs, but interact with, and are subject to, the behaviour of individuals working with and through them' (Auel and Christiansen 2015: 264).

Finally, and as far as the structure of this contribution is concerned, after this introduction, a general overview of inter-parliamentary cooperation at COSAC is presented, trying to identify the main trends that have developed since the Treaty of 
Lisbon entered into force. The third section is a critical evaluation of COSAC, its main achievements and current challenges. The fourth section of this contribution aims at a prospective exercise to question the place, the role and the importance that COSAC may have in inter-parliamentary cooperation. Finally, some conclusions are drawn, which also aim towards further reflection.

\section{Inter-parliamentary Cooperation at COSAC: General Remarks}

The role of NPs in the EU has fostered a lengthy debate at the political and institutional level and has drawn a remarkable degree of attention from the academic community, in both cases focusing the discussions on the way NPs are perceived by other actors (institutional players and academics), and less on how those parliaments (or those involved in their proceedings) see themselves.

Inter-parliamentary cooperation can be defined as a web of meetings and conferences, gathering different people at different levels (Speakers, Committees of EU Affairs, Sectoral Committees, Chairpersons), in different timeframes (annually for the Speakers' Conference, every six months for COSAC, CFSP/CSDP, EUROPOL and Economic and Financial Governance, randomly for any other format) to discuss different issues (strategic issues, European semester, topics relevant for the EP, matters of concern for NPs), without necessarily ensuring continuity and coherence along the multiple and heterogeneous lines that compose this web (Dias Pinheiro 2017).

COSAC, on its side, was established at a meeting in 16-17 November 1989 in Paris, on the initiative of Laurent FABIUS, Speaker of the French Assemblée Nationale. Fabius proposed, at the Conference of EU Speakers held in Madrid in May 1989, the creation of an inter-parliamentary body composed of members of national parliaments specialised in European affairs. Up until the first direct elections to the European Parliament (EP) in 1979, delegations to the EP were appointed by national parliaments, and parliamentarians could at the same time be members of a national parliament and the EP. The establishment of such a body was meant to re-establish the ownership of EU affairs by Parliaments, by enabling a regular exchange of information, best practices and views on European Union matters between European Affairs Committees of NPs and the EP. 
COSAC holds plenary meetings every semester, preceded by a preparatory meeting of the Chairpersons of all NP EU Affairs Committees; it is the only inter-parliamentary forum mentioned in the Treaties, in Article 10 of Protocol 1 of the Treaty of Lisbon.

In fact, COSAC was formally recognised in a Protocol on the Role of National Parliaments in the European Union of the Treaty of Amsterdam, signed in June 1997. As mentioned above, and according to Article 10 of Protocol (No 1) on the Role of National Parliaments in the European Union of the Treaty of Lisbon, COSAC 'may submit any contribution it deems appropriate for the attention of the European Parliament, the Council and the Commission. The Conference shall in addition promote the exchange of information and best practice between national Parliaments and the European Parliament, including their special committees. It may also organise interparliamentary conferences on specific topics, in particular to debate matters of common foreign and security policy, including common security and defence policy.'

In terms of composition, each national Parliament can be represented by a maximum of six Members of its Committee for Union Affairs, and the EP also has a delegation of six Members. Moreover, three members of the Parliaments of each candidate country can be invited as observers.

Therefore, the central question we aim to answer in this paper is to assess is how NPs can increase the critical level of cooperation at COSAC, needed to address the challenges they face in their daily activity of scrutiny of EU affairs: Is inter-parliamentary cooperation at this Conference currently configured to allow NPs to obtain more information and access to the policy and decision-making circuits at EU level? Are NPs benefiting from COSAC or are they, on the contrary, lagging behind and lost amidst so many meetings?

In order to find an adequate reply to these questions, the author has developed elsewhere a taxonomy of the current range of meetings in the context of interparliamentary cooperation and tries to measure the influence that national parliaments exert in each one of them (Dias Pinheiro 2017: 95-102). For the sake of comparison, the most relevant examples of meetings that currently take place were chosen, leaving aside ongoing developments (e.g. the establishment of the Joint Parliament Scrutiny Group on EUROPOL), and choosing certain criteria (legal or political basis, existence of Rules of Procedure (RoP), agenda-setting, secretariat, composition and adoption of conclusions) that allow conclusions to be drawn on the added-value and influence of national 
parliaments in scrutiny of EU affairs. The perspective adopted here considers that the influence that can be played by national parliaments stems from four main factors:

i) the Chairmanship and the place where the meeting is held;

ii) who takes the lead in the setting of the agenda;

iii) who provides the Secretariat, and

iv) the possibility of adopting conclusions or contributions, including the voting arrangements for this purpose.

To a lesser extent, the composition of delegations is also important, for two reasons:

i) if voting is involved, an adequate balance and compromise has to be found. In this context, COSAC is a fairly good example, because national parliaments and the EP are on equal footing in terms of delegations (six Members each), which has been deemed appropriate given the scope and mission of COSAC. If the adoption of any decision is made by consensus, numbers are less relevant in that a small number of parliaments is enough to block any decision;

ii) speaking time, because the larger the delegations, the less time is available for debate.

Concerning the place of COSAC in this matrix, the conclusion is that the Conference is the locale where the influence of NPs can be considered as relatively high, for the following reasons: the national Parliament who holds the Presidency has considerable room for manoeuvre in defining the agenda, i.e. topics and guests, and conducting the debates. Moreover, the Presidency is assisted by the COSAC Secretariat in all its tasks, which performs its duties under the political responsibility of the COSAC Presidency and the Presidential Troika, which comprises the three NPs of the trio and the EP, in each semester. The COSAC Secretariat, where NPs are preponderant, is the only Permanent Secretariat in inter-parliamentary cooperation in the EU. The results of its work are of considerable importance to NPs, not only in streamlining the procedures of COSAC itself but also the knowledge-enhancing output it produces (i.e. Bi-annual Reports of COSAC, background documents). Finally, the influence of NPs in COSAC is higher with regard to the Contribution adopted, not only because it is drafted by the Presidency of the Parliament, but also because, if consensus is not reached, a voting procedure follows in which no single delegation can alone block its adoption. Given that the Contribution adopted by COSAC is sent to the EU institutions, which are invited to react to points 
raised therein, NPs have been using this tool to 'gain access to' certain dossiers, calling for a reply from the institutions.

COSAC therefore occupies a central role in inter-parliamentary cooperation, especially as it is based on a governance model that gives NPs a stronger say in the running of events. As Ian Cooper also concluded in a recent work, concerning the three IPCs (IPCs), ${ }^{\text {III }}$ 'their relative strength and effectiveness may (...) be measured by three criteria - autonomy, continuity, and decision-making. When assessed in this way, clear differences emerge; COS $A C$ is the strongest of the three' (Cooper 2017).

Some NPs have taken creative initiatives with the potential to strengthen their role in EU affairs, as evidenced by three 2014 reports from: the Tweede Kamer, 'Ahead in Europe: On the role of the Dutch House of Representatives and NPs in the European Union'; ${ }^{\text {IV }}$ the House of Lords, 'The role of NPs in the European Union'; or, finally, from the Folketinget's EU Committee 'Twenty-three recommendations to strengthen the role of NPs in a changing European governance'. ${ }^{\mathrm{VI}}$

New patterns and forms of behaviour have therefore started to emerge from NPs in their adaptation to EU affairs, which might have an impact on the proceedings of COSAC; but how can they take advantage of this development, and the complex framework, to increase the critical level of cooperation needed to address the challenges they face in their daily activity of scrutiny of EU affairs? As Eva Kjaer Hansen, Chairwoman of the EU Committee of the Folketinget rightly states in the above-mentioned recommendations from the Folketinget: 'We must reduce these long and inefficient meetings with too many participants, redundant speeches, too little genuine political debate and few ground-breaking decisions'.

Consequently, COSAC has to be operational, i.e. practical and functional, innovative (i.e. with the capacity to invent new approaches), and solution-oriented (i.e. able to identify obstacles and seek ways to overcome them), exerting an enhanced influence in the overall process of policy- and decision-making at the EU level. In this context, COSAC should be developed and strengthened as a forum where parliaments can use the institutional opportunities it provides to maximise their benefits in the scrutiny of EU affairs, motivated by the possibility of having a policy impact. In a context of asymmetric access to information (Griglio and Lupo 2014), COSAC should offer NPs access to a wide range of sources and interactions that have the potential to enhance the benefits of their involvement in EU affairs. 
Against this background, this paper aims at putting forward some ideas and approaches regarding the role of COSAC in the effectiveness of inter-parliamentary cooperation. In fact, and while acknowledging that the Early Warning Mechanism (EWM) is a very important legal tool available to NPs, for it gives them a specific role in the EU decisionmaking process, it should not, however, prevent them from engaging in the policy-making process. In fact, the scrutiny of EU affairs by NPs is a dynamic process that encompasses several dimensions beyond the eight-week period dedicated to subsidiarity. For that reason, COSAC also has a role to play in the context of the recent trend that sees a shift in the motivation that drives this cooperation; here we see a gradual movement from a combination of efforts to produce a negative output, by blocking proposals on the basis of a breach of the subsidiarity principle in an EWM-obsessed way, to, more importantly, an active ex ante process proposing new paths and solutions (e.g. the green card, for instance, see below).

Thus, and for the purpose of this essay, it is more prudent to refer to COSAC as the promoter of a set of practices that has contributed to the establishment of a layer of supranational exchange of information, knowledge and ways to perform scrutiny among NPs. This process has allowed them to play a more effective role in the oversight and monitoring of a system of EU governance with increasing features of intergovernmentalism (e.g. the Fiscal Compact, the role of the European Council as an institution, the influence of the Eurogroup, etc), but which also poses new challenges for COSAC in order to be relevant and effective in the system of inter-parliamentary cooperation after the Treaty of Lisbon entered into force.

\section{COSAC: Current Challenges and Shortcomings}

COSAC should be considered as one of the most important pillars of interparliamentary cooperation. In fact, and despite a recent trend to evaluate COSAC in a negative way, emphasising the difficulties it now faces and overlooking its history and importance, COSAC has had an incomparable prominence in the affirmation of NPs within the EU system of governance since the Conference's establishment in 1989. This trend is sometimes unconsciously present, as illustrated by the introductory remarks in Chapter 1 - 'Future of COSAC' of the 21st Bi-annual report, that 'whilst interparliamentary 
cooperation has been blossoming in importance and a number of significant for a have been created in recent years, it can be argued that COSAC has not evolved significantly'. Even though the chapter itself subsequently goes in a different, and more positive, direction about COSAC, there is evidence of a certain mindset at work, in referring to it by considering its recent past only and overlooking its 25 years of history.

The COSAC Secretariat published in January 2014 a historical overview of this Conference which shows that it has been, since its origins, the only forum where, for many years, parliamentarians from all Member-States, the EP and candidate countries could meet to discuss and exchange views and best practice on the most relevant issues of European integration. $^{\text {VII }}$

It would suffice to go through the agendas of COSAC meetings to conclude how it has addressed and debated virtually every topic in EU integration, fostering an ownership of the different dossiers by NPs, promoting an exchange of views amongst them on these subjects, and bringing closer the best practice and ways of working of these Parliaments in EU affairs. ${ }^{\text {VIII }}$

One clear example of the above is the decisive role played by COSAC in the framework of the constitutional process which began with the European Convention and led to the Treaty of Lisbon. In fact, COSAC followed the proceedings of the Convention both closely and actively, because many parliamentarians participating at COSAC were at the same time representatives of their Parliaments in the Convention, which created a certain synergy between the two. This established a new layer at the EU level, not only because Parliaments were formally associated with the wider EU governance system that was steering the debate and taking the decisions (Convention), but also because it gave unprecedented momentum to cooperation and exchange between them, both at the two working groups at the Convention dedicated to NPs (WG 4) and to Subsidiarity (WG 1), but also in the multiple discussions that took place at COSAC from that moment onwards. ${ }^{\text {IX }}$

COSAC has indeed succeeded in fulfilling its mission of 'promoting the exchange of information and best practice between NPs and the EP' stated in its Rules of Procedure (Article 1.2) in several different domains. Together with the valuable acquis gathered in the biannual reports, COSAC has enabled Parliaments to enter into and maintain a level of 
exchange and cooperation amongst themselves that would not exist otherwise. Moreover, its importance is confirmed by that fact that it is explicitly mentioned by the EU Treaties.

Nevertheless, one must always bear in mind that different Parliaments expect different things from their participation in COSAC: some see the Conference playing a more active role, while others give it a lesser and more restrictive responsibility. From an empirical point view, it would be enough to attend a COSAC plenary and to observe how difficult and controversial it always is to reach agreement between 41 Parliamentary chambers and the EP on the Contribution to be adopted by the Conference.

Observation of the evolution of COSAC, and the impact and influence it has had on the advancement of the work of NPs in EU affairs, makes it clear that it has engendered a learning process among Parliaments over the years. It has provided them with comparative information and practice on how to tackle the challenges of EU integration (e.g., subsidiarity checks) and has been especially helpful in strengthening their capacities to deal with the prerogatives enshrined in the Treaty of Lisbon. Therefore, COSAC has helped to Europeanise NPs, ${ }^{\mathrm{x}}$ influencing their procedures, institutional behaviours and ownership of EU affairs. It has also assisted them in streamlining their approaches to the difficulties they have been facing in adapting to the changing environment of EU multi-level governance.

On the other hand, and without detriment to the role played by the EU Speakers' Conference, COSAC has been the main forum ensuring institutional continuity and memory, coherence and stability in inter-parliamentary cooperation. To this effect, the set up and development of the COSAC Secretariat (the only permanent secretariat of interparliamentary cooperation at EU level) has been an outstanding landmark. It is a unique feature of COSAC and one of its most important working tools, and is of benefit to all NPs and the EP.

However, COSAC faces nowadays many difficulties and challenges. Some argue that 'COSAC has not evolved significantly,' $\mathrm{XI}$ which brings about unprecedented challenges, both external and internal.

Firstly, other than the EU Speakers' Conference, COSAC had been, until very recently, the only established and structured forum of regular meetings between parliamentarians dealing with the EU. This meant that the scope of the topics COSAC could cover was quite broad, because there was no other meeting point for Members to network and exchange best practice. 
Yet, gradually, this scenario has evolved over time:

a) within the framework of the rotating EU Council Presidency, a commonly designated Parliamentary dimension of the Presidency has developed, comprising several meetings of the Chairpersons of the different sectoral Committees of all NPs;

b) the EP has widened its interaction with NPs, namely through Joint Parliamentary Meetings, Joint Committee Meetings, and meetings of corresponding Committees on specific topics;

c) after the entry into force of the Treaty of Lisbon and of the intergovernmental Treaty on Stability, Coordination and Governance (TSCG), two IPCs were established, the Conference on CFSP/CSDP and the Conference foreseen in Article 13 of the TSCG, on economic and financial governance;

d) more recently, and pursuant to Article 88 of the TFEU, the Conference of Speakers on 24 April 2017 established the Joint Parliamentary Scrutiny Group (JPSG) on the European Union Agency for Law Enforcement Cooperation (Europol).

This trend illustrates a shift in the ownership of EU issues within NPs from the sphere of the EU Affairs Committees alone towards the remit of sectoral Committees, which are more deeply involved in the monitoring of EU policies (Fromage 2017). If COSAC has played, thus far, the role of main driver, as a conduit between the elected and the electors in EU affairs, promoting more transparency and inclusiveness, it now shares the stage with multiple other Conferences that see themselves as the most appropriate forum to assure that function in the specific domains of EU integration where they operate.

This has been an interesting and positive development, because this multi-polarised system of inter-parliamentary cooperation has shaped a supranational layer of influence for NPs, where they develop ownership of matters on which their national Governments decide and negotiate at EU level, exchange information and best practice on the ways to scrutinise and monitor EU policies and gain access to information on these matters that otherwise, most likely, they would not gather in such an asymmetrical system as EU governance.

However, all of this has led to external pressure on COSAC, despite its decisive contribution to the development of tools of parliamentary scrutiny which are now of benefit to other parliamentary committees: COSAC is now faced with a certain ambiguity regarding its role and scope as a consequence of the empowerment of other forums, 
namely what place should it occupy in the constellation of inter-parliamentary cooperation in order to stay relevant?

Adding to this exogenous pressure, COSAC faces some internal dilemmas related to its own functioning. Firstly, many Parliaments ${ }^{\mathrm{XII}}$ state that the quality of the debates has been the least successful aspect of COSAC meetings, criticising the restricted time available for debate (often one minute per member) and the lengthy presentations given by some of the speakers, which are then not followed up or which do not have any concrete impact on the work of COSAC.

Secondly, COSAC is currently structured around two main events: a meeting of the Chairpersons, which is of a 'preparatory nature' and to 'be held prior to each plenary meeting', and which is attended by the Chairs of all EU affairs Committees and the relevant member of the EP; and the COSAC plenary meeting itself. As a Conference for exchange of best practice and information, COSAC would benefit from a certain degree of streamlining and coordination between these two meetings.

Thirdly, more importance should be given to the bi-annual report that each COSAC Presidency presents, because despite the intense amount of work invested by all delegations and by the COSAC Secretariat in the drafting of each report, it attracts a very low degree of attention, and is often treated like a procedural item, instead of one of COSAC's most substantial outputs.

In fact, and salient to this paper, no other IPC collects, analyses and produces such lengthy, analytical and long-lasting documents on the most relevant topics of interparliamentary cooperation as COSAC. Conclusions and contributions adopted by other IPCs - if indeed adopted - are usually documents of high political relevance, but besides receiving no reply from the EU institutions, have no critical assessment, no empirical background assembled on the basis of the replies given by Parliaments and no prospective input as the COSAC biannual report and Contribution do. For this reason, if interparliamentary cooperation is to promote a strengthening of the link between parliamentarians and citizens, bringing procedures, rules and decisions closer to the latter, it should make better use of existing tools to achieve those goals.

Fourthly, and linked to the above, the Contribution adopted by each COSAC plenary meeting and addressed to the EU institutions is the most politically visible output produced by COSAC at present. It should however be noted that, regardless of the different views 
and approaches that delegations may have towards the Contributions of COSAC, their political effectiveness was clearly demonstrated in the framework of the three yellow cards on subsidiarity issued so far (Monti II, European Public Prosecutor's office and posting of workers). In calling on the European Commission to respond directly to the concerns raised by NPs in all three cases, COSAC used Contributions to put political pressure on the Commission to react, which the latter failed to do at first but eventually did. Therefore, the Contribution, if used in a targeted and result-oriented way, can be a valuable tool at the disposal of COSAC.

The final remark in this section addresses the interaction between COSAC and other forums of inter-parliamentary cooperation, where COSAC should put special emphasis on setting up channels of communication. This would not only promote synergies, but also affirm its role within this new constellation of inter-parliamentary cooperation, or 'Euronational parliamentary system'. The same applies, with particular relevance, to dialogue and contact with the EU Speakers' Conference, given the coordination and steering role the latter plays in this context. I return to this subject with concrete proposals further below.

\section{The Contribution of COSAC to the Effectiveness of Inter- parliamentary Cooperation}

\subsection{COSAC and inter-parliamentary cooperation}

From what has been outlined above, firstly regarding inter-parliamentary cooperation as a system and, secondly, characterising COSAC and its role since its inception, what assessment can be made on the contribution of the Conference to the effectiveness of inter-parliamentary cooperation? What place has been occupied by COSAC in what can be called the 'collective scrutiny' by Parliaments of the EU: how, and indeed if, has it fostered and helped NPs and the EP share, promote and develop strategies of parliamentary oversight? Can it be perceived as the virtual third Chamber to which Cooper (2012) has referred, or, instead, is it shifting its nature towards a more generalist approach in political dialogue across the board of inter-parliamentary cooperation?

COSAC indeed looks nowadays very different from its beginning: despite the influential and decisive role it has played since then, in promoting the role of NPs in the EU, it now faces unprecedented challenges. Overcoming these challenges requires 
boldness and creativity from COSAC to reinvent itself and affirm its position in the interparliamentary construct by doing what it does best: anticipating the needs of NPs (e.g. gathering information on parliamentary practice), raising awareness on issues of common concern (e.g. democratic accountability and legitimacy), and being politically assertive in those fields where Parliaments wish to show their strength (e.g., the follow-up to the yellow cards). Finally, COSAC should strive to establish a relationship of complementarity, instead of rivalry or competition, with other IPCs.

As discussed elsewhere (Dias Pinheiro 2016: 303-310), COSAC is now facing an identity crisis, because its purpose, scope, organisation and role are currently under question. In fact, the implementation of the provisions of the Treaty of Lisbon regarding NPs and the deepening of inter-parliamentary cooperation, with new conferences (CFSP/CSDP), different topics (besides the traditional institutional issues), innovative procedures (intergovernmental Treaties) imply a profound rethinking of the role of COSAC: i) Is it a political body, aiming at steering and coordinating the role of NPs in the EU, as the only IPC foreseen in the Treaty? Or is it, instead, a forum for the mere exchange of information and best practice? ii) Where should COSAC be placed within the constellation of IPCs - is it a primus inter pares Conference or, nowadays, just one among many? iii) Which issues can/should COSAC cover - any salient EU issue it deems appropriate, or should it avoid addressing issues now under the remit of other IPCs? iv) Which relationship and communication channels should COSAC establish with these forums?

If COSAC wishes to exert a role in collective scrutiny it needs to regain its relevance within the existing EU multi-level parliamentary field (Crum and Fossum 2009). Firstly, COSAC still stands as the most stable, overarching and well-known forum of interparliamentary cooperation in the EU. One clear example of that was the fact that, within the Task Force on Subsidiarity, Proportionality and Doing Less More Efficiently ${ }^{\text {XIII }}$ established by the President of the European Commission, it was the Presidency of COSAC that was asked to appoint representatives from national Parliaments. This is a clear demonstration that the all-encompassing role the COSAC plays, plus its versatility and global approach to inter-parliamentary cooperation, are unique features that no other IPC possesses. And this is still the way that EU institutions perceive COSAC. 
The flourishing of IPCs should be regarded by COSAC as a positive development: it is a decisive step towards a specialisation of inter-parliamentary cooperation, and a deepening of Parliaments' capacity for scrutiny, that COSAC should not fear. In fact, this trend corresponds to what the EP very correctly anticipated in 2014 (in the Casini report): interparliamentary cooperation should seek to bring (at all times) the right people together at the right time to address the right issues in a meaningful way, so as to ensure that the decisions taken in the various areas of responsibility benefit from the 'added value' brought by real dialogue and proper debate. ${ }^{\text {XIV }}$

As far as COSAC is concerned, it has a unique advantage, as the sole body of interparliamentary cooperation composed only of Members that belong to the EU affairs Committees of NPs, which means that they are the ones responsible, at the national level, for dealing exclusively with EU affairs. In fact, and notwithstanding that scrutiny systems vary significantly from one Parliament to another, it is often the case that those Committees play a certain pivotal role in the EU affairs activities of each national Parliament, whereas the specialised Committees deal with EU policies but are focused narrowly within their remits. COSAC is therefore tailored for the 'big picture' of interparliamentary cooperation and this is what is has been doing with a remarkable success.

COSAC can currently bring a holistic approach to inter-parliamentary cooperation, to collective scrutiny by EU Parliaments, based on its streamlined structures and procedures; for it is acknowledged by the EU institutions to be the focus stakeholder with which to engage, and on the mere circumstance that it is still the only IPC with institutional continuity provided by its Permanent Secretariat.

4.2. Some proposals for the reform of COSAC towards more effective interparliamentary cooperation

This essay aims at putting forward some concrete ideas to release the untapped potential that COSAC still has, covering not only its current proceedings and output, but also some thoughts for further reflection on the future strengthening of COSAC.

Firstly, the choice of topics to be discussed in each meeting should focus on the issues that bring direct added-value to the scrutiny work that NPs perform: specific legislative proposals, exchange of best practice on the scrutiny of the activity of national Governments, debates on how to strengthen democratic legitimacy and accountability and exchange of views on policy fields that relate directly to the competences of NPs (e.g. 
criminal law, banking union, taxation). This should be done in such a way that every parliamentarian that attends a COSAC meeting goes home with a clear idea of what lessons were learnt during the meeting, which contacts, and channels of communication were established, and which are the most relevant political positions and trends regarding a certain dossier or policy field.

Secondly, the debates ought to be structured in a way that promotes and encourages the development of a parliamentary perspective around the topics chosen, i.e., for each panel and issue to be discussed, parliamentarians should always be included as key-note speakers, alongside Commissioners and members of national Governments.

Moreover, the Presidency should attempt, wherever possible, to steer debates towards this parliamentary perspective, in a way that enriches the scrutiny of the same policy fields or specific proposals being undertaken in national capitals. For the same reason, the Contribution to be adopted should mirror the debates and exchanges that actually took place during the meeting, seeking to influence and obtain a reply from the European institutions to the issues and concerns raised by the constituent Parliaments.

If this were to be achieved, COSAC would be uniquely placed to continue promoting a 'collective ownership' by Parliaments of the EU, prior to a stage of 'collective scrutiny' stricto sensu. In the majority of cases the focus and priorities of Parliaments differ immensely, and the fact that those priorities are not coordinated jeopardises a more structured and collective scrutiny.

To overcome this limitation and obstacle, and to fully engage in a collective scrutiny approach, it would be worth going back to a successful practice developed by COSAC prior to the entry into force of the Treaty of Lisbon: coordinated (subsidiarity) checks. In fact, COSAC coordinated three subsidiarity checks carried out under the provisions of the Treaty of Lisbon. ${ }^{\mathrm{XV}}$ The selection procedure adopted was quite simple: each Parliament would put forward two proposals for scrutiny, COSAC would gather a list of them and the one or two proposals that would gather more support would be subject to a collective scrutiny.

Unfortunately, this methodology and procedure was abandoned after the Treaty of Lisbon entered into force, for various reasons: namely a conviction among some NPs that coordinated checks would became an obsolete concept after the Treaty's entry into force, 
while others argued that it placed too much emphasis on subsidiarity from a negative standpoint, i.e., to block proposals.

This second argument should be given further consideration, namely assessing whether the idea of choosing proposals to scrutinise collectively should be revived, not necessarily only from a subsidiarity perspective, but to promote a simultaneous check on global EU issues. These might include the future of the Eurozone and its democratic accountability (e.g. a Parliament of the Economic and Monetary Union?), developments in the field of Defence and Security (e.g. the Permanent Structured Cooperation) or the repercussions of Brexit in the EU's institutional and political system.

Some might argue that this could encroach on the remit of some of the other IPCs established recently, but the proposed perspective is that it would instead create some complementarity: COSAC would not be doing the scrutiny and oversight of these policy fields on its own behalf, but gathering information, exchanging best practice and building an acquis of knowledge and literature about these areas, via the Biannual reports and the work of its Secretariat. This could benefit the reinforcement of public policies adopted by the executives, namely the decisions they take at EU level in these domains, fostering more transparency and openness, while promoting a collective scrutiny by NPs. These would be asked at a pre-defined moment in time what are they scrutinising and planning to do on these dossiers, while simultaneously allowing COSAC to build synergies and complementarity with other IPCs.

\subsection{Cooperation between COSAC and other inter-parliamentary conferences}

In the relationship of COSAC with the new IPCs and with the EU Speakers' Conference, a good practice that has been implemented in the past is worth signalling: on a number of occasions, the Presidency of the EU Speakers' Conference was invited to deliver a short briefing at the COSAC Plenary, highlighting and giving notice of its main decisions and achievements. This approach should be generalised as a standing invitation between the various Conferences (namely COSAC, CFSP/CSDP and Article 13) to host a representative from each other, to give a briefing on the latest developments and achievements within their remits. This would facilitate dialogue, create synergies, and avoid duplications, besides functioning as a confidence building measure between different players. 
A bolder move would be to expand the responsibilities of the COSAC secretariat so that it could share its secretarial support with other IPCs, which would ensure a permanency to the flow of information between them and would foster a sort of broader 'epistemic community' between the IPCs. It does not make much sense to have a permanent secretariat, with the acquis and knowledge gathered since 2004, serving only one Conference and leaving all others aside. This would involve a development of the role of the secretariat and its permanent members; but revitalising a perspective that dates from 2004 seems to me rather urgent.

Linked to this idea, shared secretarial support could serve a more proactive and analytical purpose, gathering at the end of each year the list of topics and conclusions/contributions adopted by the IPCs and producing a report with the main findings of inter-parliamentary cooperation.

If NPs really want to move towards cooperation at the COSAC level, that fosters effectiveness and a collective system, they should shape their participation in the multiple fora through ideas of coordination, interaction and complementarity - instead of rivalry and competition. IPCs should establish a constant dialogue between them, develop permanent channels to keep each other informed of their activities and build a critical mass of what Parliaments are doing and scrutinising. Otherwise, they will be rejecting their potential for effectiveness instead of bolstering it, because they only meet twice a year, are most of the time physically apart in each capital and do not engage systematically with each other.

It is here that COSAC could play a pivot role between the multiple Conferences that have been established, because it is the only one of a generalist and broad nature and therefore not bound to a specific policy domain, but instead able and capable of promoting exchanges of information, knowledge and best practice in any of them. This would not mean that COSAC would take away the responsibility of the EU Conference of Speakers as the highest coordinating political body of Inter-parliamentary Cooperation, because it is placed at another level, akin to what Heads of State and Government in the European Council represent. Furthermore, it would not establish any hierarchy of IPCs, but instead envisage a network where one of the Conferences has a remit (generalist by definition, for EU affairs Committees are responsible for the overall participation of their respective Parliaments in EU affairs), the means (a Permanent Secretariat), the institutional continuity (two meetings per semester, one of the Chairpersons and a Plenary meeting, fixed, with 
clear rules of procedure and a long-standing tradition) and the tools (the Contribution addressed to the EU institutions, to which the latter are to respond). And that Conference can only be COSAC, should COSAC wish to play that role, and the others understand the benefits and synergies of it.

In fact, we often forget that this is precisely what the Treaty clearly attributed to COSAC as its main mission: according to Article 10 of Protocol (No 1) on the Role of NPs in the European Union of the Treaty of Lisbon, COSAC 'may submit any contribution it deems appropriate for the attention of the EP, the Council and the Commission. The Conference shall in addition promote the exchange of information and best practice between NPs and the EP, including their special committees. It may also organize Conferences on specific topics, in particular to debate matters of common foreign and security policy, including common security and defence policy.' As such, COSAC has a mandate to bring other Committees closer and the spirit of the Treaty drafters even referred to the possibility of COSAC being the one who would 'organise' other IPCs. For many reasons, it was not COSAC that would organise those Conferences - and rightly so but it can be the one bringing together the cooperation between them.

4.4. COSAC and the choice of priorities for scrutiny: the Commission Work Programme

With the idea of promoting coordinated scrutiny exercises, either on subsidiarity or on a specific policy field, and the network of collaboration between IPCs to be developed in which COSAC has a key role to play, another very important step is inextricably linked to these two: the choice of priorities for scrutiny by NPs. While far from being a new topic, it is worth revisiting. In 2015, and at the initiative of the Dutch delegation at COSAC (the Tweede Kamer, at the time), all NPs were encouraged to set up a list of priorities for scrutiny based on the European Commission Work Programme (ECWP) for that year, which would then be compiled by the COSAC Secretariat and sent to the European Commission.

In the replies given to the 25th Biannual Report of COSAC, ${ }^{\mathrm{XVI}}$ the majority 'considered it either "somewhat useful" or "very useful" to produce such an annual overview to be shared with all Parliaments/Chambers and sent to the European Commission and other EU institutions'. 
During the Meeting of the Chairpersons of COSAC in January 2017, the speech delivered by the Chairman of the Dutch Senate gave an interesting insight into practices and procedures regarding the ECWP, namely that: By identifying proposals parliaments consider most important or controversial, grouping these priorities in a table and sharing them with each other and with the European Commission, we can work together as parliaments to scrutinize the proposals and to check our governments' negotiations in the Council. This indeed is at the core of the practice that we are now following in COSAC. ... While independent from each other, with each its own system and ways of doing things, we can and should learn from each other's practices, and see how - through coordination - we collectively can operate more effectively as NPs' (emphasis added). ${ }^{\mathrm{XVII}}$

COSAC should further develop and deepen this approach, namely by giving more visibility to this list of priorities, but also through sharing this information more formally with other IPCs and collecting input directly from them. In many cases, like in the Portuguese Parliament, it is the European Affairs Committee which steers the process of identifying priorities, but it is up to the specialised Committees to actually choose them. For that reason, an effective and collective scrutiny of those priorities can only occur if these alternative and creative routes of parliamentary diplomacy are implemented by NPs.

Moreover, this collective scrutiny approach could also expand to dossiers and topics other that those subject to subsidiarity review, including the substance of proposals in the light of the more ownership-oriented dynamics that the political dialogue with the European Commission has fostered in recent years.

\subsection{The Green Card Procedure}

One of the most interesting developments of inter-parliamentary cooperation in recent years was the initiative of the 'green card' which refers to the possibility for NPs to suggest a legislative initiative to the Commission. This idea seeks to capitalise on the willingness of NPs who seek greater involvement in the legislative process; this would give them the opportunity of playing a proactive role in the EU agenda-setting process and further contribute to the good functioning of the EU, in addition to existing forms of parliamentary scrutiny and involvement.

In fact, this is also a response to criticism of the yellow card procedure and the logic behind it; this is often seen as a negative process as it gives NPs a right, under certain strict conditions, to indicate that a legislative proposal should not be proceeded with. This was 
one of the key findings of the report made by the House of Lords on The Role of NPs in the European Union' issued in 2014, where the idea of a green card was firstly formally formulated, since it was found that there was 'scope for a group of NPs working together to make a constructive suggestion for an initiative. ${ }^{\text {xVIII }}$

During the COSAC Chairpersons meeting in Riga (June 2015), a mandate was given to the Luxembourg Presidency to set up a working group to strengthen political dialogue through the introduction of a 'green card' as well as the improvement of the 'yellow card' procedure. The aim was to improve existing political dialogue and encourage NPs wishing to take a proactive role to submit constructive and non-binding suggestions on policy measures or legislative proposals to the European Commission, without prejudicing its right to initiate legislation, which it had gained from NPs. ${ }^{\text {Ix }}$

The 'green card' initiative has also been officially welcomed by the Commission which indicated in its 2016 report that 'recognizes that NPs (...) play an important role in bridging the gap between European institutions and the public. The Commission continues to respect the balance between the institutions (...) and is mindful of its right of initiative. However, it has demonstrated that it is ready to consider suggestions from NPs, like their joint initiative on food waste, that indicate where action at European level could bring added benefit. $\mathrm{xx}$

The EP adopted a resolution in February 2017 where it suggested 'complementing and enhancing the powers of NPs by introducing a 'green card' procedure whereby NPs could submit legislative proposals to the Council for its consideration. ${ }^{\mathrm{XXI}}$

In this context, the EU Select Committee of the UK House of Lords sent a letter to the NPs inviting them to sign a 'pilot green card initiative' on food waste, without a specific threshold or deadline, to be sent to the European Commission. ${ }^{X X I}$ The 'green card' sent by 16 chairpersons of NPs and chambers on 22 July 2015 called upon the Commission to adopt a strategic approach to the reduction of food waste. The text drafted was itself quite innovative, because it was rather detailed in terms of policies to be implemented and procedures to be adopted, whereas these letters are usually vague.

On 17 November 2015 the Commission replied to the 'green card' promising to pay particular attention to NPs' suggestions. Moreover, in its report on Relations with NPs, the Commission went even further by highlighting that 'Some of the suggestions on food donation, data collection and monitoring were subsequently reflected in the circular economy package adopted in December 2015.' Notwithstanding this comment, if we look at the five priorities identified in 
the green card, the new Commission proposal did not in reality reflect what NPs had intended. ${ }^{\text {XXIII }}$

Two other 'green cards' were initiated, one by the French Assemblée Nationale, on EU corporate social responsibility, signed in July 2016 by seven other parliamentary chambers, and another by the Latvian Saeima on the revision of the Audiovisual Media Services Directive in November 2015. However, neither gathered much support. It is still too early to assess the effectiveness of this tool, but at this stage it seems clear that, although innovative, still needs fine-tuning in its procedures, general approach, coordination of initiatives and - again - of priorities, in order to be effective.

\subsection{COSAC and subsidiarity: the only way or another way forward?}

At this point, it is pertinent to mention a recent article by Davor Jančić in which he analyses the 'subsidiarity guardianship function of NPs' arguing that 'the current concept and practice of subsidiarity monitoring do not satisfactorily address the problem of competence creep and the need to safeguard domestic socio-economic and politico-legal idiosyncrasies. The article concludes that there should be a refocusing of parliamentary scrutiny towards the principle of conferral and legislative substance" in order to alleviate "the democratic deficit and increasing EU legitimacy' (Jančić 2015).

The arguments put forward throughout this article are very relevant for the role of COSAC, since it acknowledges that the involvement of NPs and COSAC in the early warning mechanism 'bas yielded positive results in terms of alerting NPs to the ubiquity of EU law and its legal and constitutional impact.' and that 'many domestic parliamentary chambers have become more active in scrutinizing EU affairs thanks to subsidiarity policing.' However, Jančić reminds us that this exercise is only effective in terms of collective scrutiny, for it 'bas its greatest utility if it gives rise to a constructive argument between NPs and the Commission' because 'the sheer existence of the institutional capacity for dialogue between NPs and the Commission does not suffice automatically to enhance the legitimacy of EU lawmaking' (Jančić 2015: 949).

This leads Jančić to ask exactly the same question that COSAC should ask of itself in order to be relevant and contribute to the effectiveness of inter-parliamentary cooperation: the chief conundrum of the European role of NPs is how to strike a balance between guaranteeing an area of autonomous legislative action of EU institutions and retaining a measure of meaningful influence of 
domestic legislatures. The harmony between these two strategic considerations is fundamental to the democratic legitimacy of EU decision making and its outcomes because of the distinct representative function of NPs' (Jančić 2015: 950).

Jančić then identifies what is labelled the 'straightjacket of subsidiarity', meaning that Parliaments have excessively focused their attention on the early mechanism stricto sensu and that therefore 'Subsidiarity may thus appear as a distraction from, and an undue limitation of, the classic parliamentary business' (De Wilde 2012) and that 'With more and more NPs participating in the early warning mechanism, I have argued that they have bitten the subsidiarity bait (Jančić 2013). This author could hardly agree more, adding that COSAC should assess this reality and be the promoter of a 'shift in the motivation that drives this cooperation, ie gradually evolving from a combination of efforts to produce a negative output by blocking proposals on the basis of a breach of the subsidiarity principle in a "subsidiarity-obsessed" way; to a new dynamic process that actively, proposes new paths and solutions' (Dias Pinheiro 2017: 103).

As mentioned by Jančić , while some authors like Fabbrini and Granat (2013: 117) argue that a 'a misuse of the subsidiarity review' should be avoided, advocating a narrow reading of the subsidiarity mechanism, others like Goldoni (2014: 107) and Kiiver (2012: 545; 2008: 82) argue in favour of the broadening of the early warning mechanism to put substance and content (i.e. politics) ahead of subsidiarity and procedure.

Jančić (2015: 953) then proposes that, in order to remodel this 'straightjacket of subsidiarity' approach, 'two types of reform are requisite to infuse EU law and governance with greater democratic legitimacy. One is to refocus NPs' scrutiny on the question of the existence of EU competence and the principle of conferral, and the other to endow parliaments with a more positive role as regards the substance of EU legislation. Both of these reforms would significantly contribute to the good functioning of the EU' (emphasis added).

The EWM has been one of the most visible features of the increased role played by NPs since the Treaty of Lisbon entered into force. Moreover, COSAC has been instrumental not only in promoting a learning process among Parliaments to improve their access to information and streamline their scrutiny procedures, but also in providing the opportunity to meet and exchange views on specific legislative dossiers. Nevertheless, it can also be argued that, in order to improve its effectiveness in inter-parliamentary cooperation, Parliaments and COSAC should move away from the attraction of subsidiarity, as important as might be, towards a more positive and forward-thinking role. 
In fact, COSAC is the only Conference with the membership (EU affairs Committees and a generalist and broader political approach), the institutional continuity and memory, and the means (biannual report and Contribution) to place 'Parliaments on the offensive'. Of the many proposals put forward by NPs in recent years, ${ }^{\text {xxIv }}$ alluded to profusely in a previous work (Dias Pinheiro 2017: 103), Jančić labels the proliferation of initiatives as the 'Game of cards' of NPs, with particular emphasis not only to the green card, but also to what he calls the 'late card'. This would be a final check system, which would allow national Parliaments to re-examine EU legislative proposals at the end of the EU legislative procedure, just before their enactment, thus serving, in Jančić's view, as a 'political complement to judicial review of subsidiarity compliance. Since NPs would thus gain a ratifying rather than an enabling function in the EU legislative process, the late card would give their pronouncements more weight than in a purely early warning mechanism.'

This late card system, in order to be effective, would require a substantially different approach from NPs collectively. In fact, this requires focusing not only on the initial stage of the legislative procedure (the 8 week-period to issue a reasoned opinion), but also being able to follow and monitor the sometimes-lengthy negotiation process between EU institutions while at same time holding its national governments to account on the outcome of the compromises reached. In fact, even if a yellow or orange card were not triggered, this integrated scrutiny approach might even lead to Parliaments more seriously considering the activation of what is foreseen by Article 8 of the Protocol on the Application of the Principles of Subsidiarity and Proportionality, according to which 'The Court of Justice of the European Union shall have jurisdiction in actions on grounds of infringement of the principle of subsidiarity by a legislative act, brought in accordance with the rules laid down in Article 263 of the Treaty on the Functioning of the European Union by Member States, or notified by them in accordance with their legal order on behalf of their national Parliament or a chamber thereof.'

According to this reasoning, if the 'late card' were to lead Parliaments, collectively, to consider that their requests on subsidiarity grounds had not been met, they could individually decide - in accordance with their internal constitutional and legal requirements - to take the matter to Court. It is here that COSAC, with its extensive experience with institutional matters and coordinating collective checks, would be uniquely placed to promote this joint scrutiny. 
In fact, and to sum up, all of this can be steered and led by COSAC, with no need for Treaty change or a mandate given by any other Conference. Furthermore, a very recent development might just give COSAC the political and institutional push it needs.

\subsection{The Timmermans task-force on subsidiarity: COSAC as the NPs' voice}

In fact, expectations are high on the side of NPs, with some of them taking a more proactive lead within the framework of COSAC. Following an initiative of the Danish Parliament in tabling its twenty-three recommendations on the role of NPs in changing European Governance, a group of twenty-nine Chairpersons of EU Affairs Committees of different NPs addressed a letter to Jean-Claude Juncker, then President-designate of the European Commission, about cooperation with NPs. In this letter, sent on 30 June 2014, the signatories 'call on the new European Commission to set up a working group, to include national parliamentarians and representatives of the EU institutions, to look at the role of NPs in the EU. The task of the working group should be to draft an action plan on ways to strengthen the role of NPs in the European Union.' $\mathrm{xxv}$

This clear demand by NPs for the establishment of a working group was not implemented. Nevertheless, a new possibility has opened up recently that NPs and COSAC, in particular, should embrace: the President of the European Commission announced, in his State of the Union speech on 13 September 2017, the establishment of a Task Force on Subsidiarity, Proportionality and 'Doing Less More Efficiently', as part of the Commission's work towards a more united, stronger and more democratic Union. ${ }^{\mathrm{x} v \mathrm{I}}$ The Commission asked for the appointment of three members from NPs to participate, via a letter from President Juncker to the Estonian Presidency of COSAC. In spite of the predictably passionate debate held at the COSAC meeting in Tallin over the representation of NPs at this Task Force, ${ }^{\text {XVII }}$ ultimately COSAC will be the Conference representing NPs' views at this forum.

COSAC thus has a great opportunity, and indeed a significant responsibility, to influence the outcome of this task force - several contributions have already been tabled by NPs over the last years, assembling experience, knowledge and practice that can now finally be put on the table. COSAC should take this exercise seriously and with the most robust political assertion possible. The final result of this task-force might be a bold step in the direction that this essay calls for: inter-parliamentary cooperation benefiting from politically 
substantial feedback from the EU institutions which allows for NPs and the EP to share, promote and develop joint strategies of parliamentary oversight.

Some of the conclusions and proposals of the final report to this Task Force, symbolically titled 'Active subsidiarity - a new way of working, ${ }^{\text {,XVIII }}$, point in that direction. Even though the report should, as Vice-President Timmermans puts it in the foreword to the above mentioned report, not be seen as 'an end in itself' but 'the start of a process to open up our procedures more to the local and regional level', it contains ideas which might shape the future of inter-parliamentary cooperation. Out of the nine recommendations put forward, some might have direct implications on the way NPs exert their scrutiny and will most likely require them to adapt to new responsibilities. For instance, recommendation \#1 states that 'A common method ("assessment grid") should be used by the Union's institutions and bodies and by national and regional Parliaments to assess issues linked to the principles of subsidiarity (including $E U$ added value), proportionality and the legal basis of new and existing legislation [capturing] the criteria contained in the Protocol on subsidiarity and proportionality originally attached to the Amsterdam Treaty and relevant jurisprudence of the European Court of Justice.' A concrete model is proposed and annexed the report in which it is recommended that During the legislative process, the European Parliament and the Council should systematically review the subsidiarity and proportionality of draft legislation and the amendments they make using the common method. They should take full account of the Commission's assessment presented in its proposals as well as the (reasoned) opinions of national Parliaments and the European Committee of the Regions.'

This is a rather bold initiative, for it acknowledges something NPs have demanded for a long time, i.e., that the opinions could and should address issues other than subsidiarity and, at the same time, presents the idea of some streamlining on the criteria to issue those opinions.

Recommendation \#6 states that the co-legislators 'should use consistently the subsidiarity grid during their negotiations' and that 'the Commission should highlight (...) any views it receives from local and regional authorities'. Moreover, recommendation \#3 recognises that 'The Commission should apply flexibly the Treaty-based 8 weeks deadline for national Parliaments to submit their reasoned opinions' taking account of 'common holiday periods and recess periods' and determining that the Commission should 'respond as far as possible, within 8 weeks of receiving each opinion', which would be a positive outcome, given the delays that currently exist. 
Other recommendations address issues such as: the need to raise national, local and regional authorities' awareness of the opportunities to engage at an early stage of the decision-making process; the responsibility of the Commission in ensuring that its assessments consider territorial impacts; and the linkage between platforms like REGPEX, designed to support the participation of regions with legislative powers in the early phase of the EU legislative procedure, the Early Warning System, and IPEX, the platform for the mutual exchange of information between the national Parliaments and the European Parliament concerning issues related to the European Union, especially in light of the provisions of the Treaty of Lisbon.. Finally, the report recommends that the Commission develop a mechanism to identify and evaluate legislation from the perspective of subsidiarity, proportionality, simplification, legislative density and the role of local and regional authorities, and also calls on the next Commission, along with the EP and the Council, to reflect the need for more effective implementation, rather than initiating new legislation in areas where the existing body of legislation is mature and/or has recently been substantially revised.

COSAC should immediately take the lead in the debate in the merits and implementation of these recommendations.

\section{Conclusion}

Ten years after the Treaty of Lisbon was signed, a multi-polarised system of interparliamentary cooperation has emerged, characterised by the empowerment of other Committees in the scrutiny of sectoral EU affairs, the establishment of other IPCs and the changing role ascribed to the previous sole drivers of that cooperation, i.e. COSAC and NPs' EU Affairs Committees.

The point of view presented here is that COSAC should occupy a leading role in that system, especially as it is based on a governance model that gives NPs a stronger say in the running of events. In fact, collective scrutiny is also the capacity of IPCs to organise themselves in an open and constructive way, not narrowly focused in their specific policy domain, but with a level of awareness of the global implications of inter-parliamentary cooperation. In this respect, COSAC is the IPC with the 'global picture' and therefore in a 
unique position, not only to coordinate the work of other IPCs, but also to establish a level of outreach towards them that brings coherence to the overall system.

The proposals presented in this paper point in that direction, namely with regard to a reform of the proceedings of COSAC meetings, promoting the selection of topics to address that brings direct added-value to the scrutiny work that NPs perform and that promotes a political and parliamentary perspective around those issues; this will promote a coordinated assessment of different policy dossiers (legislative and non-legislative, e.g. future of eurozone, Brexit).

Regarding cooperation between Conferences, this paper advocates that a standing invitation be established between the various Conferences (namely COSAC, CFSP/CSDP and Article 13) to host a representative from each other in order to give a briefing on the latest developments and achievements within their remits, building confidence and facilitating dialogue. On a more ambitious note, the responsibilities of the COSAC secretariat should be expanded to support other IPCs, with a more proactive and analytical ambit, gathering at the end of each year the list of topics and conclusions/contribution adopted by the IPCs and producing a report with the main findings of inter-parliamentary cooperation.

This leads to a final remark - the effectiveness of COSAC depends not only on what NPs are capable of doing by themselves, in streamlining their procedures and scrutiny systems or even agreeing with the establishment of new inter-parliamentary fora, but also on the response, and engagement, of the European institutions to this process. In fact, a lot has been done by the EU institutions since the Treaty of Lisbon entered into force to enhance the role of NPs from a legal and procedural point of view. However, a lot remains to be done concerning their actual political response, namely from the European Commission, in taking into due consideration the contribution of Parliaments in EU public policies. Regardless of the different views that NPs have on EU issues, notwithstanding the prerogatives and responsibilities that they ought to exert at the national level, there is an EU parliamentary dimension to decision making and to the implementation of EU public policies that cannot be politically neglected by EU institutions. Hopefully, future essays of this sort will shift academic attention towards the analysis of what the EU institutions are doing to promote inter-parliamentary cooperation as a truly effective bidirectional exercise. 


\footnotetext{
* The views expressed here are strictly personal and not bind or reflect in any way the political and institutional position of the Portuguese Assembleia da República.

I Article 12 of the Treaty on the European Union.

II The author has also published some academic research on the topic of inter-parliamentary cooperation: see Dias Pinheiro 2012.

III CFSP/CSDP, Article 13, and COSAC

IV Published on 9 May 2014, available at https://www.houseofrepresentatives.nl/news/report-ahead-europeadopted-house-representatives.

\begin{tabular}{llllll}
\hline P & Published & March & available & at
\end{tabular}
} https://publications.parliament.uk/pa/ld201314/ldselect/ldeucom/151/15102.htm.

VI Published in January 2014, available at http://renginiai.lrs.lt/renginiai/EventDocument/6fa11f98-fc154443-8f3f-9a9b26d34c97/Folketing Twenty-three\%20recommendations EN.pdf.

VII Available

http://www.cosac.eu/documents/History $\% 20$ of $\% 20$ COSAC $\% 20$ NOVEMBER $\% 202015 \% 20$ EN.pdf.

VIII http://www.cosac.eu/documents/bi-annual-reports-of-cosac/.

IX The full report of the working groups and its proceedings is available at http://europeanconvention.europa.eu/EN/doc wg/doc wg2352.html?lang=EN.

$\mathrm{x}$ We follow the concept of Europeanisation as defined in the works of Auel and Benz (2005), Besselink (2007), Raunio and Wiberg (2010), and Kiiver (2006).

XI $21^{\text {st }}$ COSAC bi-annual report.

XII For instance, the replies to the 21 st COSAC bi-annual report.

XIII The press release on the set-up of this Group is available at http://europa.eu/rapid/press-release IP-174621 en.htm

XIV EP resolution of 16 April 2014 on relations between the EP and the NPs, available at: www.europarl.europa.eu/sides/getDoc.do?type=TA\&language=EN\&reference=P7-TA-2014-0430.

$\mathrm{xV}$ The previous two subsidiarity checks under the Treaty of Lisbon were conducted on the Proposal for a Framework Decision on Combating Terrorism $\operatorname{COM(2007)~} 650$ final and on the Proposal for a Council Directive implementing the principle of equal treatment between persons irrespective of religion or belief, disability, age or sexual orientation $\operatorname{COM}(2008) 426$ final.

XVI Available at http://www.cosac.eu/55-the-netherlands-2016/lv-cosac-12-14-june-2016-the-hague/d19\%2025th $\% 20$ Bi-Annual $\% 20$ Report $\% 20$ of $\% 20$ COSAC $\% 20$ EN.pdf.

XVII Full transcript of the speech available at https://parl.eu2017.mt/en/Events/Documents/COSAC $\% 20$ Speech $\% 20$ session $\% 20 \mathrm{II} \% 20$ on $\% 20$ the $\% 20 \mathrm{C}$ WP\%20Bastiaan\%20VAN\%20APELDOORN.pdf.

XVIII Full report available at https://publications.parliament.uk/pa/ld201314/ldselect/ldeucom/151/151.pdf. XIX Presidency of the Council of the European Union, Grand Duchy of Luxembourg, 2015. Information Note in relation to the COSAC Working Group, 'Green card' (enhanced political dialogue) http://www.eu2015parl.lu/Uploads/Documents/Doc/114 2 Information note Green card 20151026.pdf. xx Annual Report from the Commission relations with national Parliaments (2015), available at https://ec.europa.eu/transparency/regdoc/rep/1/2016/EN/1-2016-471-EN-F1-1.PDF.

XXI Available at http://www.europarl.europa.eu/sides/getDoc.do?pubRef=-//EP//TEXT+TA+P8-TA2017-0048+0+DOC+XML+V0//EN, paragraph 60 .

XxII The full text of the letter is available at http://www.parliament.uk/documents/lords-committees/euselect/green-card/green-card-letter-to-np-chairs.pdf.

XXIII These five priorities were: 1. EU Food Donation Guidelines for food donors and food banks; 2. An EU co-ordination mechanism to support the sharing of best practices between Member States on food waste prevention, reduction and management strategies; 3. European Commission monitoring of the business-tobusiness cross-border food supply chain; 4. A European Commission recommendation on the definition of food waste and on data collection; and 5. The establishment of a horizontal working group within the Commission.

XXIV For instance the report from the Tweede Kamer, 'Ahead in Europe: On the role of the Dutch House of Representatives and NPs in the European Union', 9 May 2014; From the European Union Committee of the House of Lords, 'The role of NPs in the European Union', 24 Mar. 2014, HL 151 2013-2014; or the work from the Folketinget, European Affairs Committee, 'Twenty-three recommendations to strengthen the role of NPs in a changing European governance', Jan. 2014. 
xxv The full letter is available at: http://www.parliament.uk/documents/lords-committees/euselect/Role $\% 20$ of $\% 20$ national $\% 20$ parliaments/Joint-letter-to-President-Juncker.pdf.

XXVI The press release on the set-up of this Group is available at http://europa.eu/rapid/press-release IP-174621 en.htm.

XXVII For further reading, the minutes of the COSAC meeting in Tallin are quite elucidating http://www.cosac.eu/58-estonia-2017/lviii-cosac-26-28-november-2017-tallinn/i19\%20Minutes $\% 20$ of $\% 20$ the $\% 20$ meeting $\% 20$ of $\% 20$ the $\% 20$ LVIII $\% 20$ COSAC $\% 20$ Tallinn.pdf. XXVIII The full report is available at https://ec.europa.eu/commission/sites/beta-political/files/report-taskforce-subsidiarity-proportionality-doing-less-more-efficiently 1.pdf.

\section{References}

- Auel Katrin and Benz Arthur, 2005, 'The Politics of Adaptation: the Europeanisation of National Parliamentary Systems', Journal of Legislative Studies, XI(3-4): 372-393.

- Auel Katrin and Christiansen Thomas, 2015, 'After Lisbon: NPs in the European Union', West European Politics, XXXVIII(2): 261-281.

- $\quad$ Besselink Leonard, 2007, A composite European Constitution, Europa Law Publishing, Groningen.

- Cooper Ian, 2012, 'A "Virtual Third Chamber” for the European Union? National Parliaments after the Treaty of Lisbon', West European Politics, XXXV(3): 441-465.

- $\quad$ Cooper Ian, 2017, 'The IPCs of the EU: discussion forums or oversight bodies?' (draft).

- Crum Ben and Fossum John Erik, 2009, 'The Multilevel Parliamentary Field: a framework for theorizing representative democracy in the EU', European Political Science Review, I(2): 249-271.

- De Wilde Pieter, 2012, 'Why the early warning mechanism does not alleviate the democratic deficit', OPAL Online Paper, No. 6/2012.

- Dias Pinheiro Bruno, 2012, The Treaty of Lisbon and the adaptation of NPs to the challenges of European integration: the case of the permanent representatives of NPs to the EU institutions, ISCSP, Lisbon, abstract available at https://www.repository.utl.pt/bitstream/10400.5/5124/1/ABSTRACT\%20Bruno\%20Dias\%20Pinheiro\%5 $\underline{\mathrm{b} 1 \% 5 \mathrm{~d} . \mathrm{pdf}}$.

- Dias Pinheiro Bruno, 2016, 'The Role of COSAC in the Changing Environment of National Parliaments in the EU: An Identity Crisis?', in Lupo Nicola and Fasone Cristina (eds), Interparliamentary Cooperation in the Composite European Constitution, Hart Publishing, Oxford, 303-310.

- Dias Pinheiro Bruno, 2017, 'Interparliamentary Cooperation between NPs', in Jonsson Cornell Anna and Goldoni Marco (eds), National and Regional Parliaments in the EU-Legislative Procedure Post-Lisbon: The Impact of the Early Warning Mechanism, Hart Publishing, Oxford, 87-113.

- Fabbrini Federico and Granat Katarzyna, 2013, "Yellow card, but no foul": The role of the NPs under the Subsidiarity Protocol and the Commission proposal for an EU regulation on the right to strike', Common Market L aw Review, L(1): 115-143.

- $\quad$ Fromage Diane, 2017, 'Standing committees in interparliamentary cooperation in the post-Lisbon era: towards the end of the European Affairs Committees' predominance?', in Lupo Nicola and Fasone Cristina (eds), Interparliamentary Cooperation in the Composite European Constitution, Hart Publishing, Oxford, 113-130.

- Goldoni Marco, 2014, 'The early warning system and the Monti II Regulation: The case for a political interpretation', European Constitutional Law Review, X(1): 90-108.

- Griglio Elena and Lupo Nicola, 2014, 'Towards and asymmetric EU, without an asymmetric EP', Working Paper Series, LUISS Guido Carli School of Government.

- Jančić Davor, 2013, 'NPs in the EU: Biting the subsidiarity bait?', International Journal of Constitutional Law Blog, 25 Sept. 2013, www.iconnectblog.com/2013/09/national-parliaments-in-the-eu-biting-thesubsidiarity-bait.

- Jančić Davor, 2015, 'The Game of Cards: NPs in the EU and the future of the early warning mechanism and the political dialogue', Common Market Law Review, LII(4): 939-975.

- $\quad$ Kiiver Philipp, 2006, National parliaments in the European Union: a critical view on EU constitution-building, Aspen Publishers, Frederick MD. 
- Kiiver Philipp, 2008, 'The Treaty of Lisbon, the National Parliaments, and the Principle of Subsidiarity', Maastricht Journal of European and Comparative Law, XV(1): 77-83.

- $\quad$ Kiiver Philipp, 2012, 'The conduct of subsidiarity checks of EU legislative proposals by NPs: Analysis, observations and practical recommendation', ERA Forum, XII: 535-547.

- Raunio Tapio and Wiberg Matti, 2010, 'How to Measure the Europeanisation of a National Legislature?', Scandinavian Political Studies, XXXIII(1): 74-92. 